\title{
Hypoxic Ischemic Encephalopathy, AE
}

National Cancer Institute

\section{Source}

National Cancer Institute. Hypoxic Ischemic Encephalopathy, AE. NCI Thesaurus. Code C154945.

An adverse event in a newborn characterized by injury to the central nervous system that occurs when there is insufficient delivery of oxygen to all or part of the brain. 